\title{
Prevalence of Multidrug Resistance Non-Typhoidal Salmonellae Isolated from Layer Farms and Humans in Egypt
}

\author{
Mohamed Said Diab ${ }^{1 *}$, Rania Samir Zaki ${ }^{2}$, Nermin A. Ibrahim ${ }^{3}$ and Mohamed S. Abd El Hafez ${ }^{4}$ \\ ${ }^{1}$ Department of Animal Hygiene and Zoonoses, Faculty of Veterinary Medicine, New Valley University, Egypt \\ ${ }^{2}$ Department of Food Hygiene, Veterinary Medicine, New Valley University, Egypt \\ ${ }^{3}$ Department of Bacteriology, Mycology, and Immunology, Faculty of Veterinary Medicine, Mansoura University, Egypt \\ ${ }^{4}$ Poultry Diseases Department, Faculty of Veterinary Medicine, New Valley University, Egypt \\ *Corresponding Author's E-mail: mohameddiab333@gmail.com; (D) ORCiD: 0000-0002-4878-1534
}

\begin{abstract}
Non-Typhoidal Salmonella (NTS) are substantial foodborne pathogens that lead to bacteremia, gastroenteritis, and focal infection. Poultry is one of the usual provenances for the development of multidrug-resistance NTS. This problem has increased in developing countries with the indiscriminate use of antibiotics in the poultry production system. The current study aimed to determine the prevalence and tendency of antimicrobial resistance of zoonotic Salmonella spp. A total of 601 samples, including cloacal samples (150) eggshell (150), egg content (15 pooled samples), layer hen carcasses (150), hand swab (68) and stool samples (68) from poultry workers, were collected from five layer chicken farms. Isolation of NTS was performed by using different cultural and biochemical methods. Moreover, Salmonella isolates were evaluated for antimicrobial susceptibility using the disc diffusion method. The cloacal samples and stool samples showed the prevalence of Salmonella spp. at approximately similar rates of $4.7 \%$ and $4.4 \%$, respectively. Chicken isolates were identified as $S$. Enteritidis, $S$. Typhimurium, and $S$. Gallinarum while the human isolates were only $S$. Typhimurium and $S$. Enteritidis. The prevalence of the NTS on the surface of the eggshells (7.3\%) was higher than that in the other samples. Among 12 antimicrobials tested, $86.4 \%$ resistance was found to streptomycin and oxytetracycline followed by neomycin and erythromycin (77.3\%), norfloxacin and ampicillin $(68.2 \%$ ) across the study sites. Kanamycin and gentamicin remained sensitive by $95.5 \%$ and $90.9 \%$, respectively. The present study indicated that layer chickens and its products are important sources for human infection with multiple-drug resistant NTS strains.
\end{abstract}

Key words: Antibiotic sensitivity, Egg, Layer poultry, Non-typhoidal Salmonella, Zoonoses

\section{INTRODUCTION}

According to (Marcus et al., 2007), Salmonella species are the most frequent cause of foodborne gastrointestinal infections in the human community. Salmonella is readily transmitted through water, vegetables, fish, hamburger, pork, poultry products including eggs and chicken meat (Pires et al., 2014). Among these, chicken meat and eggs are the kinds of food that regularly cause salmonellosis (Jackson et al., 2013; Middleton et al., 2014; Phagoo and Neetoo, 2015). Therefore, the food chain, especially poultry-derived foods, can be considered as a major public health issue; if they serve as a route for the advent and dispersion of resistant bacteria including Salmonella species in the environment (Mossie and Dires, 2016; Oloso et al., 2018; Ramatla, et al., 2019).

The eggs might be contaminated with salmonella by two different routes, the first route is vertical transmission from an infected hen before oviposition. The second route is horizontal transmission through contaminated feces or environmental dust and then penetration of microorganisms to the egg through the eggshell. Thusly, the microorganism remains on the farm for long periods and poor eggshell quality can lead to foodborne illness (Al Momani et al., 2018).

Salmonellosis in poultry is essentially asymptomatic, however nonspecific signs, including anorexia, depression, dropping wings, diarrhea, and reduced egg production may be apparent (Gast and Beard 1992; Ezema et al., 2009; Eguale 2018).

NTS is one of the most prevalent foodborne infections around the world, causing diarrhea, fever, vomiting, and sometimes even death. The WHO has estimated that the NTS is responsible for an average number of 78.7 million foodborne diseases with more than 59000 deaths annually. Additionally, it is the most widely recognized cause for foodborne infections in the Middle East and North Africa (Johnson et al., 2014; Havelaar et al., 2015).

In the poultry industry, antibiotics have been used widely as growth promoters, prophylaxis, and therapeutic agents. the widespread and indiscriminate use of antibiotics is a contributing element for the development of antibiotic-resistant pathogens (Davis et al., 2011; Manyi-Loh et al., 2018). However, the utilization of antimicrobial for growth promotion is prohibited in the European Union but allowed in the USA, Canada and in Many countries (Gyles, 2008).

In the course of recent years, the emergence of multi-drug resistant bacteria such as salmonellae has become a major global health concern (McWhorter and Chousalkar, 2015). WHO has reported high levels of antimicrobial 
resistance involving salmonellae due to several factors such as substandard treatments, self-prescriptions, and nonadherence to medications (Dar et al., 2016). Increment in antimicrobial resistance interferes with the prevention and control of such organisms, consequently represent a danger to public health (Langata et al., 2019).

Actually, the poultry and poultry products have a great role in the dissemination of antimicrobial-resistant zoonotic pathogens. Subsequently, the objective of the present study was to isolate and identify NTS from layers, eggs, and human. Also, this study evaluated the sensitivity of the isolated salmonellae to diverse antimicrobials.

\section{MATERIALS AND METHODS}

The current study was conducted in El-Behira Governorate, Egypt.

\section{Ethical approval}

All procedures performed in this study, including the collection of human and animal samples were in accordance with the Egyptian ethical standards of the National Research Committee. All human subjects gave their informed oral consent for the collection of fecal samples, with the agreement that any identifying information of the persons should not be published.

\section{Sample collection \\ Cloacal samples}

To collect the cloacal samples, both wings of the birds were held with one hand, so that the tail portion remained in the upper direction. Then, the sterile swab was inserted into the cloaca of the ISA Brown hens. One hundred and fifty cloacal swab samples were collected and inoculated promptly into Buffered Peptone Water (BPW; HiMedia, India).

\section{Egg samples}

One hundred and fifty egg samples were collected from five farms (30 eggs per farm) from three sites on each farm; front, center and posterior. All eggs in individual sterile plastic bags were aseptically transported to the laboratory for the cultivation and isolation in less than six hours. Egg surface and substance were handled by the FDA's Bacteriological Analytical Manual (FDA 2012) with slight adjustments. Quickly, the whole outside surface of each egg was swabbed with a dampened swab, after that plunged in $9 \mathrm{ml} \mathrm{BPW}$, and incubated for 18 to $24 \mathrm{~h}$ at $37^{\circ} \mathrm{C}$. After that, the eggs were submerged in disinfectant comprising of 70\% alcohol and tincture of iodine (in 3:1 proportion) for 10 seconds, then permitted to air dry. Each egg was fire cleaned at the pointed end and aired out utilizing the sharp edge of a sterile surgical blade. The substance was filled with a sterile Whirl-Pak stomacher pack. The pooled 10 eggs were mixed with sterile tools by gloved hands until the yolk completely blended with the albumen. Then samples were kept at room temperature for 4 days after that $25 \mathrm{ml}$ from each sample was added to $225 \mathrm{ml}$ of tryptic soy broth supplemented with 7.8 $\mathrm{g}$ of ferrous sulfate (Sigma, United Kingdom) and incubated for $24 \pm 2 \mathrm{~h}$ at $35^{\circ} \mathrm{C}$.

\section{Laying hens carcasses samples}

One hundred and fifty laying hen carcasses were collected from five farms. All the carcasses collected after slaughtering and transferred in isolated ice bags to the laboratory for further processing. All the samples were examined within $6 \mathrm{~h}$ after the collection. An equal amount of $25 \mathrm{~g}$ of each sample was added to $225 \mathrm{ml}$ of BPW and mixed well by a homogenizer and incubated at $37^{\circ} \mathrm{C}$ for $18-24 \mathrm{~h}$ (ISO6579, 2002).

\section{Human samples}

Sixty-eight stool samples, as well as 68 hand swabs, were collected from workers and visitors on the farm. Each stool specimen was received in a sterile plastic container and immediately transferred in an icebox to the laboratory where further preparation and analysis were performed. each swab of the stool was inoculated into $45 \mathrm{ml} \mathrm{BPW}$ and incubated at $37^{\circ} \mathrm{C}$ for $18 \mathrm{~h}$ (Andoh et al., 2017).

\section{Isolation and identification of Salmonella spp.}

\section{Non-selective pre-enrichment}

All the swab samples and the layer hen meat samples after processing was pre-enriched in BPW in the ratio of one to nine and incubated at $37{ }^{\circ} \mathrm{C}$ for $18-24 \mathrm{~h}$.

\section{Selective enrichment}

The selective enrichment medium of Rappaport-Vassiliadis (RV) (HiMedia, India) was used for the isolation of Salmonella spp. than bacterial colonies having similar cultural characteristics. The $0.1 \mathrm{ml}$ of pre-enriched sample was transferred into a tube containing $10 \mathrm{ml}$ of RV broth and incubated at $42{ }^{\circ} \mathrm{C}$ for $24 \mathrm{~h}$.

\section{Plating out and identification}

After enrichment, a 10 $\mu 1$ loopful of inoculums was streaked onto Xylose Lysine Desoxycholate (XLD) agar (HiMedia, India) and brilliant green agar (BGA; HiMedia, India) and incubated at $37^{\circ} \mathrm{C}$ for $24 \mathrm{~h}$. Next, the plates were 
evaluated for the presence of typical and suspect Salmonella colonies, according to the colony characteristics described in (ISO6579, 2002).

\section{Biochemical tests}

The presumptive colonies of Salmonella were also identified based on biochemical tests panel including urease broth, triple sugar iron, methyl red, indole, Voges-Proskauer, and Citrate test, in accordance with standard test protocol described in FDA's Bacteriological Analytical Manual (FDA, 2012).

\section{Serotyping of isolates}

The serotyping of biochemically confirmed isolates was performed by slide agglutination test according to the method described by (Kauffmann, 1974).

\section{Antimicrobial susceptibility testing}

Twelve antimicrobial agents were analyzed using concentrations detailed in table 1 . The antimicrobial sensibility profiles of the isolates were determined using the disk diffusion method on Mueller-Hinton agar (HiMedia, India), elaborated by the Clinical and Laboratory Standards Institute (2015).

Table 1. Antimicrobial discs, concentration, and interpretation of results for isolated Salmonella strains.

\begin{tabular}{lcccc}
\hline \multirow{2}{*}{ Antimicrobial agent } & Sensitivity disc content $(\boldsymbol{\mu g})$ & \multicolumn{3}{c}{$\begin{array}{c}\text { Interpretation of results } \\
\text { (Zone diameter; mm) }\end{array}$} \\
\cline { 3 - 5 } & & Resistant & Intermediate & Susceptible \\
\hline Amoxicillin & 30 & 14 or less & $15-18$ & 19 or more \\
Ampicillin & 10 & 13 or less & $14-17$ & 18 or more \\
Chloramphenicol & 30 & 12 or less & $13-17$ & 18 or more \\
Ciprofloxacin & 5 & 15 or less & $15-19$ & 20 or more \\
Erythromycin & 15 & 13 or less & $14-22$ & 23 or more \\
Gentamicin & 10 & 12 or less & $13-14$ & 15 or more \\
Kanamycin & 30 & 13 or less & $14-17$ & 18 or more \\
Nalidixic acid & 30 & 13 or less & $14-18$ & 19 or more \\
Neomycin & 30 & 12 or less & $13-16$ & 17 or more \\
Norfloxacin & 10 & 12 or less & $13-15$ & 16 or more \\
Oxytetracycline & 30 & 14 or less & $15-18$ & 19 or more \\
Streptomycin & 10 & 11 or less & $12-14$ & 15 or more
\end{tabular}

\section{RESULTS}

Table 2 shows the prevalence of Salmonella spp. in collected samples. The highest prevalence rate (7.3\%) was found in the eggshell. However, the Salmonella spp. not isolated from egg content and layer hen carcasses. The cloacal samples and the fecal samples showed the prevalence of Salmonella spp. at nearly similar rates of $4.7 \%$ and $4.4 \%$, respectively. As shown in table 3, the poultry isolates were $S$. Enteritidis, $S$. Typhimurium and $S$. Gallinarum, while human isolates were $S$. Enteritidis and $S$. Typhimurium.

Table 4 showed that the majority of isolates were highly susceptible to kanamycin (95.5\%), gentamicin (90.9\%), nalidixic acid (77.3\%) and ciprofloxacin (72.7\%). Moreover, poor susceptibility to neomycin, amoxicillin, and erythromycin was detected among the isolated Salmonella. On the other hand, according to the obtained results in the current study, Salmonella spp. represented a high resistance rate of $86.4 \%$ to streptomycin and oxytetracycline, and $77.3 \%$ to neomycin and erythromycin. In total, $68.2 \%$ of isolates were resistant to amoxicillin, ampicillin, and norfloxacin. Moreover, $18.2 \%$ exhibited resistance to chloramphenicol and nalidixic acid. According to the results presented in table 5, in layer isolates, $S$. Enteritidis was the most resistant serovar to antibiotic followed by $S$. Typhimurium and $S$. Gallinarum. However, the data presented in table 6 indicated that human isolates were highly resistant to neomycin and norfloxacin, while they were highly susceptible to gentamicin, kanamycin, and nalidixic acid.

Table 2. Prevalence of Salmonella spp. in samples obtained from layer farms in Egypt

\begin{tabular}{|c|c|c|c|c|c|c|}
\hline & Cloacal & Eggshell & Egg content & $\begin{array}{c}\text { Layer hen } \\
\text { carcasses }\end{array}$ & $\begin{array}{c}\text { Workers } \\
\text { hand swab }\end{array}$ & $\begin{array}{c}\text { human stool } \\
\text { samples }\end{array}$ \\
\hline $\begin{array}{l}\text { Number of } \\
\text { samples }\end{array}$ & 150 & $\begin{array}{c}150 \\
\text { (30 eggs per farm) }\end{array}$ & $\begin{array}{c}15 \text { pooled samples (each } \\
\text { sample included } 10 \text { eggs) }\end{array}$ & 150 & 68 & 68 \\
\hline $\begin{array}{l}\text { Isolation } \\
\text { rate }\end{array}$ & $7(4.7 \%)$ & $11(7.3 \%)$ & 0 & 0 & $1(1.5 \%)$ & $3(4.4 \%)$ \\
\hline
\end{tabular}


Table 3. Prevalence of Salmonella serotypes in human and chicken samples obtained from layer farms in Egypt

\begin{tabular}{lcccc}
\hline Species & Serotype & $\begin{array}{c}\text { S. Enteritidis } \\
(\mathrm{n})\end{array}$ & $\begin{array}{c}\boldsymbol{S} \text {. Typhimurium } \\
(\mathrm{n})\end{array}$ & $\begin{array}{c}\text { S. Gallinarum } \\
(\mathrm{n})\end{array}$ \\
\hline Chicken & 8 & 7 & 3 \\
Human & 2 & 2 & 0 \\
\hline
\end{tabular}

n: number

Table 4. Antimicrobial susceptibility profiles of Salmonella spp. isolated from layer farms in Egypt

\begin{tabular}{lccc}
\hline Antibiotics & $\begin{array}{c}\text { Number of susceptible } \\
\text { isolates (\%) }\end{array}$ & $\begin{array}{c}\text { Number of intermediate } \\
\text { isolates (\%) }\end{array}$ & $\begin{array}{c}\text { Number of resistant } \\
\text { isolates }(\%)\end{array}$ \\
\hline Neomycin & $1(4.5)$ & $4(18.2)$ & $17(77.3)$ \\
Gentamicin & $20(90.9)$ & $2(9.1)$ & $(0)$ \\
Streptomycin & $1(4.5)$ & $2(9.1)$ & $19(86.4)$ \\
Kanamycin & $21(95.5)$ & $1(4.5)$ & 0 \\
Chloramphenicol & $12(54.5)$ & $6(27.3)$ & $4(18.2)$ \\
Nalidixic acid & $17(77.3)$ & $1(4.5)$ & $4(18.2)$ \\
Ciprofloxacin & $16(72.7)$ & $4(18.2)$ & $2(9.1)$ \\
Norfloxacin & $3(13.6)$ & $4(18.2)$ & $15(68.2)$ \\
Oxytetracycline & $1(4.5)$ & $2(9.1)$ & $19(86.4)$ \\
Amoxicillin & $1(4.5)$ & $6(27.3)$ & $15(68.2)$ \\
Ampicillin & $2(9.1)$ & $5(22.7)$ & $15(68.2)$ \\
Erythromycin & $1(4.5)$ & $4(18.2)$ & $17(77.3)$ \\
\hline
\end{tabular}

Table 5. Distribution of Salmonella serovars in layer chicken isolates and rate of resistance to antimicrobial agents

\begin{tabular}{lccc}
\hline \multirow{2}{*}{ Antimicrobial agents } & \multicolumn{2}{c}{ Number of resistant Salmonella serovars $(\%)$} \\
\cline { 2 - 4 } & S. Enteritidis & S.Typhimurium & S. Gallinarum \\
\hline Neomycin & $8(100)$ & $4(57.1)$ & $1(33.3)$ \\
Gentamicin & 0 & 0 & 0 \\
Streptomycin & $8(100)$ & $5(71.4)$ & $3(66.7)$ \\
Kanamycin & 0 & 0 & 0 \\
Chloramphenicol & $1(12.5)$ & $1(14.3)$ & 0 \\
Nalidixic acid & $3(37.5)$ & $1(14.3)$ & 0 \\
Ciprofloxacin & $0(0)$ & $1(11.1)$ & 0 \\
Norfloxacin & $7(87.5)$ & $3(42.9)$ & $1(33.3)$ \\
Oxytetracycline & $8(100)$ & $6(85.7)$ & $2(66.7)$ \\
Amoxicillin & $7(87.5)$ & $5(71.4)$ & $1(33.3)$ \\
Ampicillin & $6(75)$ & $4(57.1)$ & $2(66.7)$ \\
Erythromycin & $8(100)$ & $4(57.1)$ & $3(100)$ \\
\hline
\end{tabular}

Table 6. Distribution of Salmonella serovars in human isolates from layer farms and rate of resistance to antimicrobial agents

\begin{tabular}{lcc}
\hline \multirow{2}{*}{ Antimicrobial agents } & Number of resistant Salmonella serovars (\%) \\
\cline { 2 - 3 } & S. Enteritidis & S.Typhimurium \\
\hline Neomycin & $2(100)$ & $2(100)$ \\
Gentamicin & 0 & 0 \\
Streptomycin & $2(100)$ & $1(50)$ \\
Kanamycin & 0 & 0 \\
Chloramphenicol & $2(100)$ & $0(0)$ \\
Nalidixic acid & $0(0)$ & $0(0)$ \\
Ciprofloxacin & $1(50)$ & $0(0)$ \\
Norfloxacin & $2(100)$ & $2(100)$ \\
Oxytetracycline & $2(100)$ & $1(50)$ \\
Amoxicillin & $1(50)$ & $1(50)$ \\
Ampicillin & $1(50)$ & $2(100)$ \\
Erythromycin & $1(50)$ & $1(50)$ \\
\hline
\end{tabular}


Salmonellosis is one of the most important foodborne diseases in humans, which has been increasing in recent years (Harsha et al., 2011). Salmonellosis can be transmitted through the food chain, especially poultry products in the absence of proper hygiene and infection control practices (Ifeanyichukwu et al., 2016; Ramatla et al., 2019). Contaminated feces excreted into the environment could be a source of the bacteria to naive hosts, sustaining its existence over the layer farm environment, therefore, feces played an important role in Salmonella dispersal (Carrique-Mas and Davies 2008; Oloso et al., 2018). The present research assessed the prevalence and antimicrobial susceptibility profile of Salmonella serovars ( $S$. Typhimurium, $S$. Enteritidis, and $S$. Gallinarum) isolated from the cloacal samples, eggshell, hand swab and stool samples of workers.

The investigation of cloacal samples in the present study showed a low presence of Salmonella spp. (4.7\%), in agreement with (Garcia et al., 2011) who reported the presence of Salmonella in the cloacal samples by $4 \%$. On the contrary, higher rates of $7.33 \%$ and $\mathbf{1 4 . 6 3 \%}$ were reported by (Parvej et al., 2016) and (Bordoloi et al., 2017), respectively. The possible reason for the low prevalence of Salmonella in the present study may be due to the reality that most of the studied poultry farms were small-scale farms. The cloaca is a significant source related to the later infection of the eggshells (El-Tras et al., 2010). In addition, the surface of the eggshell could be contaminated through the litter or even during storage, transportation, and handling (Mahmud et al., 2016).

In the current study, the Salmonella had a higher prevalence in eggshells (7.3\%) compared to the other samples, while it was not recovered from the egg contents. These findings are consistent with obtained results in a study by ElFeky et al. (2013) who reported a similar isolation rate (7.83\%) of Salmonella from the eggshells and also they found that Salmonella was not detected from egg content. However, EL-Kholy et al. (2014) reported that Salmonella could not be isolated from both the eggshell and the egg content. El-Prince et al. (2019) found that the prevalence of Salmonella from the eggshells and egg contents was $1.43 \%$. The absence of Salmonella in the egg content is due to the protective barrier of the egg membranes and antibacterial constituents (Mahmud et al., 2016). It was found that the positive samples of Salmonella from the eggshells may be due to cross-contamination with feces, the cage or the farm environment (Harsha et al., 2011). The isolation rate of Salmonella from eggshells and egg contents in the present study was lower than those in reports by other studies (Akhtar et al., 2010; Ifeanyichukwu et al., 2016; Mahmud et al., 2016; Long et al., 2017). Microbial contamination of the egg has a substantial consequence in the poultry industry, particularly considering international trade. It also has severe public health importance with regard to the transmission of illness to humans, which could lead to mild symptoms or life-threatening conditions (Okorie-Kanu et al., 2016).

Chicken contamination occurs horizontally through litter, dust, food, water as well as other contaminated equipment (Tabo et al., 2013). In the current research, Salmonella spp. were not detected in the meat of layer hen, which is in agreement with previous reports (EFSA, 2013; Lamas et al., 2016). The rate of Salmonella isolation was $28.3 \%$ and 34.37\% in studies by Li et al. (2013) and Djeffal et al. (2018), respectively.

Human salmonellosis is a crucial health problem in both developed and developing countries around the world. The NTS has been the major cause of secondary bacteremia accompanied by gastroenteritis. The incidence of typhoid salmonellosis is steady, although, the prevalence of non-typhoid salmonellosis is expanding worldwide (Soltan Dallal et al., 2016). In the present study, the isolation rate of salmonella serovars from the worker's hand and stools were 1.4 and $4.4 \%$, respectively. Personal hand contamination is actually a result of limited personal hygiene supplies and poor handwashing habits (Abdi et al., 2017). The results obtained in the current study were nearly similar to Sousa et al. (2013) who found that the prevalence of Salmonella in children was 3.2\% (S. Typhimurium 60\%, S. Enteritidis $20 \%$ and S. enterica 20\%). In similar, Shaaban et al. (2018) reported Salmonella prevalence in humans was 5\%. While Farahani et al. (2018) demonstrated a higher prevalence (7\%) of Salmonella among the children. Furthermore, Soltan Dallal et al. (2016) declared that $S$. Enteritidis was the frequent isolate among humans.

The $S$. Gallinarum is a causative agent of fowl typhoid (Kwon et al., 2000). The $S$. Typhimurium and $S$. Enteritidis cause illness in humans, usually persist sub-clinical in layer birds (Quiun et al., 2002). In the current study, the prevalence of Salmonella serotypes including $S$. Enteritidis, $S$. Gallinarum, and $S$. Typhimurium was $16.6 \%, 14.4 \%$, and $38.8 \%$, respectively. While the prevalence of Salmonella (S. Typhimurium, S. Enteritidis) in human samples was $11.11 \%$ of each serotype. The Serotyping of a total of 206 Salmonella isolates by Akhtar et al. (2010) showed a high prevalence of $S$. Enteritidis among poultry (75\%) and human $(75.86 \%)$ samples. The prevalence rates of other serovars such as $S$. Typhimurium, S. Paratyphi B, S. Pullorum and non-typable salmonellae were less than $25 \%$ of the total isolates. Although all serotypes are considered potential human pathogens, the majority of infections are due to a very limited number of serotypes, of which $S$. Enteritidis and $S$. Typhimurium are the two most common ones integrated with the gastrointestinal disease of humans (Deng et al., 2012).

Bacterial resistance to antimicrobial drugs is one of the major risks for global public health, which develops due to many reasons such as misuse of antimicrobials (Okorie-Kanu et al., 2016). The antibiotic susceptibility test carried on Salmonella isolated from different samples in the present study revealed that all the isolates were multidrug-resistant to 
more than $75 \%$ of the tested antibiotics. Moreover, Salmonella serovars showed reduced susceptibility to streptomycin, oxytetracycline, neomycin, amoxicillin, and ampicillin. This finding is consistent with the results of Okorie-Kanu et al. (2016) who reported the resistance of Salmonella spp. to penicillin G, oxacillin, and tetracyclines (100\%), while was found to be highly susceptible to neomycin. The resistance of salmonella to the erythromycin, amoxicillin, oxytetracycline was reported in previous studies (Akhtar et al., 2010; Harsha et al., 2011; Phagoo and Neetoo, 2015; Islam et al., 2016; Yizengaw 2016). The general high prevalence of resistance to these antimicrobials can also be due to the uncontrolled and extensive use of these antibiotics as mainly growth promoters since the farmers have limitless access to these agents (Adesiyun et al., 1993). In addition, the uncontrolled increase in the usage of prescription antibiotics frequently purchased and used by unqualified practitioners in the veterinary and public health sectors. Also, absence of compliance and monitoring of the antimicrobial drug in developing countries and the utilization of the antimicrobial drugs at sub-therapeutic or prophylactic dosage in food animals may assist in the development and spread of antimicrobial resistance genes in Salmonella as well as other human and animal pathogens (Abdi et al., 2017).

The most effective drugs in the current study were kanamycin, gentamicin followed by nalidixic acid, ciprofloxacin, and chloramphenicol. This may be attributed to the very limited use of these antibiotics in the layer farms in the current period. Similarly, Abdi et al. (2017) indicated that gentamicin is still effective against Salmonella regardless of the time or location of the study. Ramatla et al. (2019) reported that $4 \%$ of Salmonella isolates were resistant to gentamicin. On the other side, Abunna et al. (2016) and Akhtar et al. (2010) were detected resistant to kanamycin, nalidixic acid, and chloramphenicol. This inconsistency may be attributed to the antimicrobial drug usage pattern in their study areas, which may be varied from that in the present study area. Antibiotic sensitivity test results presented in table 6 showed that some human isolates are 100\% resistant to certain antibiotics such as neomycin and chloramphenicol, despite their limited use in the human field. This finding illustrates the pivotal role of poultry farms in transmitting the infection to humans (Shang et al., 2018). The results of the antibiotic sensitivity test suggested the guidelines for both physicians and veterinarians to select the relevant antibiotics to diminish antibiotic resistance among NTS which have industrial and public health significance. This helps prevent the development of antimicrobial resistance through mutation and acquisition of resistance encoding genes (Fluit, 2005).

\section{CONCLUSION}

The findings of the present study detected the presence of multidrug-resistant salmonellae ( $S$. Enteritidis, $S$. Typhimurium, and $S$. Gallinarum) in both layer and human isolates. The multidrug-resistant salmonellae with regards to the zoonotic potential of salmonellosis could be an emerging health problem. Further research on major risk factors and molecular characterization is required to identify the genes responsible for the pathogenicity and the antimicrobial resistance in Salmonella spp. isolated from food animals and humans.

\section{DECLARATION}

\section{Competing interests}

The authors declare that they have no competing interests

\section{Authors' contributions}

Mohamed S. Diab, Rania Samir Zaki, and Mohamed S. Abd El Hafez conceived and designed the experiments. Mohamed S. Abd El Hafez, Rania Samir Zaki performed the experiments. Mohamed S. Abd El Hafez analyzed the data. Mohamed S. Diab and Rania Samir Zaki contributed reagents, materials, and analysis tools. Mohamed S. Diab and Rania Samir Zaki wrote the paper.

\section{REFERENCES}

Abdi RD, Mengstie F, Beyi AF, Beyene T, Waktole H, Mammo B, Dinka Ayana D and Abunna F (2017). Determination of the sources and antimicrobial resistance patterns of Salmonella isolated from the poultry industry in Southern Ethiopia. BMC Infectious Diseases, 17: 352. DOI: https://doi.org/10.1186/s12879-017-2437-2

Abunna F, Bedasa M, Beyene T, Ayana D and Mamo R (2016). Salmonella: Isolation and antimicrobial susceptibility tests on isolates collected from poultry farms in and around Modjo, Central Oromia, and Ethiopia. Journal of Animal and Poultry Sciences, 5(52): 21-35. Available at: http://www.JAPSC.com

Adesiyun AA, Kaminjolo JS, Loregnard R and Kitson-Piggott W (1993). Epidemiology of Salmonella infections in Trinidadian livestock farms. Revue Dev de médecine vétérinaire des pays tropicaux, 46(3): 435-437.

Akhtar F, Hussain I, Khan A and Rahman S (2010). Prevalence and antibiogram studies of Salmonella enteritidis isolated from human and poultry sources. Pakistan Veterinary Journal, 30: 25-28. Available at: http://www.pvj.com.pk

Al Momani W, Janakat S and Khatatbeh M (2018). Bacterial contamination of table eggs sold in Jordanian markets. Pakistan Journal of Nutrition, 17: 15-20. DOI: https://doi.org/10.3923/pjn.2018.15.20 
Andoh LA, Ahmed S, Olsen JE, Obiri-Danso K, Newman MJ, Opintan JA, Barco L and Dalsgaard A (2017). Prevalence and characterization of Salmonella among humans in Ghana. Tropical medicine and health, 45: 3. DOI: https://10.1186/s41182-0170043-Z

Bordoloi S, Anju N and Varsha Sand Singh RV (2017). Identification of biofilm-forming Salmonella species of layers from Tribal area of Hoshangabad District of Madhya Pradesh. Journal of Animal Research, 7: 1001-1007. DOI: https://10.5958/2277940X.2017.00151.6.

Carrique-Mas J and Davies R (2008). Sampling and bacteriological detection of Salmonella in poultry and poultry premises: a review. Revue Scientifique et Technique, 27: 665. DOI: https://10.20506/rst.27.3.1829

Clinical and Laboratory Standards Institute (2015). Performance Standards for antimicrobial susceptibility testing; twenty-fifth informational supplement. CLSI document M100-S25 Wayne, PA: Clinical and Laboratory Standards Institute.

Dar OA, Hasan R, Schlundt J, Harbarth S, Caleo G, Dar FK, Littmann J, Rweyemamu M, Buckley EJ and Shahid M (2016). Exploring the evidence base for national and regional policy interventions to combat resistance. The Lancet, 387: 285-295. DOI: https://10.1016/S0140-6736(15)00520-6

Davis MF, Price LB, Liu CM-H and Silbergeld EK (2011). An ecological perspective on US industrial poultry production: the role of anthropogenic ecosystems on the emergence of drug-resistant bacteria from agricultural environments. Current opinion in microbiology, 14 (3): 244-250. DOI: https://10.1016/j.mib.2011.04.003

Deng X, Ran L, Wu S, Ke B, He D, Yang X, Zhang Y, Ke C, Klena JD and Yan M (2012). Laboratory-based surveillance of nontyphoidal Salmonella infections in Guangdong Province, China. Foodborne Pathogens and Disease, 9: 305-312. DOI: https://10.1089/fpd.2011.1008

Djeffal S, Mamache B, Elgroud R, Hireche S and Bouaziz O (2018). Prevalence and risk factors for Salmonella spp. contamination in broiler chicken farms and slaughterhouses in the northeast of Algeria. Veterinary World, 11: 1102-1108. DOI: https://10.14202/vetworld.2018.1102-1108.

EFSA (2013). Scientific report of EFSA and ECDC. The European Union summary report on trends and sources of zoonoses, zoonotic agents and food-borne outbreaks in 2001. EFSA Journal, 11: 3129. DOI: https://10.2903/j.efsa.2015.3991

Eguale T (2018). Non-typhoidal Salmonella serovars in poultry farms in central Ethiopia: prevalence and antimicrobial resistance. BMC Veterinary Research, 14(1):217 DOI: https://doi.org/10.1186/s12917-018-1539-4

El-Feky MA, Hassan MA, Mohamed WA and Ibrahim NH and Rashwan RS (2013). Detection of Non-Typhoidal Salmonella Isolated From Food Products and Clinical Cases by PCR and Conventional Methods: A Comparative Study. Egyptian Journal of Medical Microbiology, 22: 81-92. DOI: https://10.12816/0004965

EL-Kholy AM, Hassan GM and Dalia MA (2014). Microbiological quality of poultry farm table eggs in Beni Suef city, Egypt. Assiut Veterinary Medical Journal, 60 (142): 10-13.

El-Prince E, Hussein MF and El-Rahman AMA (2019). Incidence of Salmonella species in table eggs and some egg-based products. Journal of Advanced Veterinary Research, 9: 1-7.

El-Tras WF, Tayel AA and Samir A (2010). Potential zoonotic pathways of Salmonella Enteritidis in laying farms. Vector Borne Zoonotic Disease, 10: 739-742. DOI: https://10.1089/vbz.2009.0080

Ezema WS, Onuoha E and Chah KF (2009). Observations on an outbreak of fowl typhoid in commercial laying birds in Udi, South Eastern Nigeria. Comparative Clinical Pathology, 18: 395-398.DOI: https://10.1007/s00580-009-0812-0.

Farahani NN, Jazi FM, Nikmanesh B, Asadolahi P and Kalani BS and Amirmozafari N (2018). Prevalence and antibiotic susceptibility patterns of Salmonella and Shigella species isolated from pediatric diarrhea in Tehran. Archives of Pediatric Infectious Diseases, 6: 57328. DOI: https://10.5812/pedinfect.57328.

Food and Drug Administration (FDA) (2012). FDA's bacteriological analytical manual (BAM). Chapter 5, Salmonella, Washington, DC.

Fluit A (2005). Towards more virulent and antibiotic-resistant Salmonella. FEMS Immunology and Medical Microbiology, 43(1): 111. DOI: https://doi.org/10.1016/j.femsim.2004.10.007

Garcia C, Soriano JM, Benitez V and Catala-Gregori P (2011). assessment of Salmonella spp. in feces, cloacal swabs, and eggs (eggshell and content separately) from a laying hen farm. Poultry Science, 90: 1581-1585. DOI: https://10.3382/ps.2010-01104.

Gast RK and Beard C (1992). Evaluation of a chick mortality model for predicting the consequences of Salmonella Enteritidis infections in laying hens. Poultry Science, 71: 281-287. DOI: https://10.3382/ps.0710281

Gyles CL (2008). Antimicrobial resistance in selected bacteria from poultry. Animal Health Research Reviews, 9: 149-158. DOI: https://10.1017/S1466252308001552

Harsha H, Reshmi R, Rinoy Varghese DP and AA MRKaMH (2011). Prevalence and antibiotic resistance of Salmonella from the eggs of commercial samples, Journal of Microbiology and Infectious Diseases, 1 (3): 93-100. DOI: 10.5799/ahinjs.02.2011.03.0023

Havelaar AH, Kirk MD, Torgerson PR, Gibb HJ, Hald T, Lake RJ, Praet N, Bellinger DC, de Silva NR, Gargouri N et al. (2015). World health organization global estimates and regional comparisons of the burden of foodborne disease in 2010. PLOS Medicine, 12: e1001923. DOI: https://10.1371/journal.pmed.1001923.

Ifeanyichukwu I, Chika E, Ogonna A, Chidinma I, Monique A, Ikechukwu M, Stanley E, Emmanuel N, Ngozi A and Agabus N (2016). Prevalence and antibiogram of Salmonella species isolated from poultry products in Ebonyi State, Nigeria. Journal of $\begin{array}{llllll}\text { Advanced } & \text { Veterinary } & \text { and } & \text { 3nimal } & \text { Available }\end{array}$ at:https://www.banglajol.info/index.php/JAVAR/article/view/31516

Islam MJ, Mahbub-E-Elahi ATM, Ahmed T and Hasan MK (2016). Isolation and identification of Salmonella spp. from broiler and their antibiogram study in Sylhet, Bangladesh. Journal of Applied Biology and Biotechnology, 4: 46-51. DOI: https://10.7324/jabb.2016.40308 
ISO6579 (2002). Microbiology of food and animal feeding stuffs-horizontal method for the detection of Salmonella spp. International Organization for Standardization (ISO). Geneva: 511-525.

Jackson BR, Griffin PM, Cole D, Walsh KA and Chai SJ (2013). Outbreak-associated Salmonella enterica serotypes and food commodities, United States, 1998-2008. Emerging infectious diseases, 19: 1239. DOI: https://10.3201/eid1908.121511

Johnson NB, Hayes LD, Brown K, Hoo EC and Ethier KA (2014). CDC National Health Report: leading causes of morbidity and mortality and associated behavioral risk and protective factors. The United States, 2005-2013.

Kauffmann F (1974). Serological diagnosis of Salmonella species Kauffmann White Scheme Minkagarord, Copenhagen, Denmark.

Kwon HJ, Park KY, Yoo HS, Park JY, Park YH, Kim SJ (2000). Differentiation of Salmonella enterica serotype Gallinarum biotype Gullorumfrom biotype Gallinarumby analysis of phase 1 flagellin C gene (fliC). Journal of Microbiology Methods, 40: 33-38. DOI: https://10.1016/s0167-7012(99)00129-3

Lamas A, Fernandez-No IC, Miranda JM, Vázquez B, Cepeda A, Franco CM (2016). Prevalence, molecular characterization and antimicrobial resistance of Salmonella serovars isolated from Northeastern Spanish broiler flocks (2011-2015). Poultry Science, 95: 2097-2105. DOI: https://10.3382/ps/pew150

Langata LM, Maingi JM, Musonye HA, Kiiru J and Nyamache AK (2019). Antimicrobial resistance genes in Salmonella and Escherichia coli isolates from chicken droppings in Nairobi, Kenya. BMC Research Notes, 12: 22. DOI: https://10.1186/s13104019-4068-8

Li R, Lai J, Wang Y, Liu S, Li Y, Liu K, Shen J and Wu C (2013). Prevalence and characterization of Salmonella species isolated from pigs, ducks and chickens in Sichuan Province, China. International Journal of Food Microbiology, 163: 14-18. DOI: https://10.1016/j.ijfoodmicro.2013.01.020.

Long M, Yu H, Chen L, Wu G, Zhao S, Deng W, Chen S, Zhou K, Liu S and He L (2017). Recovery of Salmonella isolated from eggs and the commercial layer farms. Gut pathogens, 9: 74. DOI: https://doi.org/10.1186/s13099-017-0223-8

Mahmud T, Hassan MH, Alam M, Khan MM and Bari MSaI A (2016). Prevalence and multidrug-resistant pattern of Salmonella from the eggs and egg-storing trays of retail markets of Bangladesh. International Journal of One Health, 2: 7-11. DOI: https://10.14202/IJOH.2016.7-11

Manyi-Loh C, Mamphweli S, Meyer E and Okoh A (2018). Antibiotic use in agriculture and its consequential resistance in environmental sources: potential public health implications. Molecules, 23: 795. DOI: https://10.3390/molecules23040795

Marcus, R, Varma, JK, Medus, C, Boothe, EJ, Anderson, BJ, Crume, T, Fullerton, KE, Moore, MR, White, PL, Lyszkowicz, E, Voetsch, AC and Angulo, FJ (2007). Re-assessment of risk factors for sporadic Salmonella serotype Enteritidis infections: a casecontrol study in five FoodNet sites, 2002-2003. Epidemiology and Infection, 135: 84-92.

McWhorter AR and Chousalkar KK (2015). Comparative phenotypic and genotypic virulence of Salmonella strains isolated from Australian layer farms. Frontiers in Microbiology, 6:12. DOI: https://10.3389/fmicb.2015.00012.

Middleton D, Savage R, Tighe M, Vrbova L, Walton R, Whitfield Y, Varga C, Lee B, Rosella L and Dhar B (2014). Risk factors for sporadic domestically acquired Salmonella serovar Enteritidis infections: a case-control study in Ontario, Canada, 2011. Epidemiology and Infection, 142: 1411-1421. DOI: https://doi.org/10.1017/S0950268813001945

Mossie T and Dires A (2016). Prevalence of antimicrobial resistant salmonellae isolated from bulk milk of dairy cows in and around Debre-Zeit, Ethiopia. World's Veterinary Journal, 6 (3): 110-116. DOI: https://10.5455/wvj.20160875

Okorie-Kanu OJ, Ezenduka EV, Okorie-Kanu CO and Ugwu UJ (2016). Occurrence and antimicrobial resistance of pathogenic Escherichia coli and Salmonella spp. in retail raw table eggs sold for human consumption in Enugu state, Nigeria. Veterinary World, 9: 1312-1319.DOI: https://10.14202/vetworld.2016.1312-1319.

Oloso NO, Fagbo S, Garbati M, Olonitola SO, Awosanya EJ, Aworh MK, Adamu H, Odetokun IA and Fasina FO (2018). Antimicrobial Resistance in Food Animals and the Environment in Nigeria: A Review. International Journal of Environmental Research and Public Health, 15: 1284. DOI: https://10.3390/ijerph15061284.

Parvej M, Nazir KHMNH, Rahman MB, Jahan M, Khan MFR and MR (2016). Prevalence and characterization of multi-drug resistant Salmonella enterica serovar Gallinarum biovar Pullorum and Gallinarum from chicken. Veterinary World, 9: 65-70. DOI: https://10.14202/vetworld.2016.65-70.

Phagoo L and Neetoo H (2015). Antibiotic resistance of Salmonella in poultry farms of Mauritius. The Journal of Worlds Poultry Research, 5 (3): 42-47.

Pires SM, Vieira AR, Hald T and Cole D (2014). Source attribution of human salmonellosis: an overview of methods and estimates. Foodborne Pathogens and Disease, 11: 667-676. DOI: https://10.1089/fpd.2014.1744

Quiun P, Markey B, Carter M, Donnelly W and Leonard F (2002). Veterinary microbiology and microbial diseases. USA: Blackwell Publishing Company.

Ramatla T, Taioe MO, Thekisoe OM and Syakalima M (2019). Confirmation of antimicrobial resistance by using resistance genes of isolated Salmonella spp. In chicken houses of North West, South Africa. World's Veterinary Journal, 9 (3): 158-165. DOI: https://dx.doi.org/10.36380/scil.2019.wvj20

Shaaban SI, Ayoub MA, Ghorbal SH and Nossair M (2018). Calves as a Reservoir of Some Diarrheagenic Agents for Human Contacts in El-Behira Province. Alexandria Journal for Veterinary Sciences, 56(2): 48-53. DOI: https://10.5455/ajvs.285867

Shang K, Wei B and Kang M (2018). Distribution and dissemination of antimicrobial-resistant Salmonella in broiler farms with or without enrofloxacin use. BMC Veterinary Research, 14: 257. DOI: https://10.1186/s12917-018-1590-1.

Soltan Dallal M, Khalilian M, Masoumi Asl H, Bakhtiari R, Davoodabadi A, Sharifi Yazdi M and Torabi Bonabi P (2016). Molecular Epidemiology and antimicrobial resistance of Salmonella spp. isolated from resident patients in Mazandaran Province, Northern Iran. Journal of Food Quality and Hazards Control, 3: 146-151. Available at: http://jfqhc.ssu.ac.ir/article-1-290-en.html 
Sousa MAB, Mendes EN, Penna FJ, Péret-Filho LA and Magalhães PP (2013). Acute diarrhea associated with Salmonella enterica in Belo Horizonte-MG: prevalence and characterization of isolates. Jornal Brasileiro de Patologia e Medicina Laboratorial, 49(1): 34-38. DOI: http://dx.doi.org/10.1590/S1676-24442013000100005

Tabo DA, Diguuimbaye CD, Granier SA, Moury F, Brisabois A, Elgroud R and Millemann Y (2013). Prevalence and antimicrobial resistance of non-typhoidal Salmonella farms in N'Djamena, Chad.Veterinary microbiology, 166(1-2): 293-298. DOI: https://10.1016/j.vetmic.2013.05.010

Yizengaw HA (2016). Isolation, Identification, and antimicrobial susceptibility testing of Salmonella from selected poultry farms in Debre Zeit. Value in Health, 19(3): A313. DOI: https://doi.org/10.1016/j.jval.2016.03.993 